\title{
Spiritual side of advertising and values of regional media products
}

\author{
Svetlana Aleksandrovna Rzhanova* \\ National Research Mordovian State University n.a. N.P. Ogarev, Saransk, Mordovia, Russia
}

\begin{abstract}
The paper considers advertising communication in the aspect of socio-cultural activity. The study shows that advertising reflects the desire of the Russian society for a global association, for the fulfillment of universal human values, performs the functions of social communication, and has signs of a media product. Special attention is paid to the spiritual side of advertising, since it reflects the new vital needs of a person, an active influence on the way of life, the system of values of individuals. It is proved that the media represent media opportunities for the implementation of advertising. Media technologies for transmitting non-verbal information, digitalization of mass media, online mode expand the communicative capabilities of advertising activities. The entire information and advertising process is reflected in the development of regional advertising and communication channels. At the moment, the regional media space of Mordovia offers such types of advertising as commercial, institutional, industrial, consumer. It should be noted that the digital indicators reflect a stable, consistent movement of regional society from the industrialsocial to the public-consumer stage of development. This confirms the fact that a fairly large number of media platforms are occupied by consumer advertising. Industrial advertising is characterized by the steady growth, which is somewhat characterized by "downturns", which may be explained by seasonal changes in the functioning of joint-stock companies. In general, the small growth in industrial production steadily achieved by the Republic of Mordovia over the past ten years is reflected in the qualitative and quantitative improvement of the corresponding type of advertising.
\end{abstract}

\section{Introduction}

The role of advertising in the modern dynamically developing world is great, because it is it, along with the media, that on the one hand, serves an indicator of change in Russia, and on the other, advertising reflects the desire of the Russian society for global unification, for the fulfillment of universal human values that are the core of human existence and large-scale management in modern historical times.

These include the recognition of life, freedom, justice, honesty, mutual respect and care. The pursuit of these values in practice may lead to a change in the world neighborhood of people inhabiting the planet based on economic exchange and improved communications in which people are united by spiritual rather than material values. If you consider the spiritual side of advertising, then it shows the new vital needs of a person, while exerting a psychological influence. This can be seen in the desire of a person to purchase a bright and beautiful product, which he sees in a particular commercial or on the pages of advertising publications.

Advertising in the media system is a constantly working segment that attracts our attention everywhere. Advertising information in the modern media space covers most forms of human life. The audience is included in the system of public relations on the interaction of two subjects - communicator and communicants (audience). A dialogue should be considered as a form of relationship in advertising communication.

In order to achieve the goal, the advertisement seeks to reach the consciousness of a potential buyer, and then to convince him. Over the past 50 years, the nature of the system of these attempts has changed thus leading to the synthesis by which advertising, to induce consumer demand to make a purchase process, paints its own related image that meets epy expectations; the expectations depend on the socio-cultural environment only, and therefore, play a regulatory role, and advertising should adapt to them. With the help of advertising, the advertiser strives so that the consumer has a desire to purchase, thereby awakening the hidden needs.

A conveyor is the main principle of the advertising industry. Advertising helps the customer attract the audience. The product is the end result, one of the main components of building a brand. The product is what in other words "was ordered" and what should first satisfy the customer.

The variety of methods and means in the market of advertising services create a strong competition. The

Corresponding author: rzanova@mail.ru 
consequence of this process was the emergence and search for new mechanisms of influence. One of the most advanced ways in the competition for the attention of the audience and the consumer was the process of forming a media brand.

The appearance of the media brand allows recognizing it, absorbing it. Media brands leave certain stories in the mind of the buyer. These can be memories of emotions received when using the product or the place and time when this product was purchased. Advertising communications to an important extent determine our image and style of life.

\section{Problem Statement}

In the late $90 \mathrm{~s}$ of the $20^{\text {th }}$ century, an information and advertising surge occurred in Russia, which led to a transformation in the socio-economic and spiritual-moral life of the country, as well as changes in the moral values of society.

The press in Russia quickly joined the developing advertising business. It is widely known that now $75 \%$ of the profits of any print publication and $100 \%$ of television revenues are provided by advertising. Advertising helps a person to decide faster and better orient in the field of goods.

There is a special industry - "marketing", which represents the organizational function and a set of processes for creating and promoting a certain product, as well as regulating relations with buyers and organizations [5].

Media marketing is a relatively new direction in the promotion of advertising products. However, it is gaining momentum over the years. Due to the lack of development of this segment of the market for goods and services, there is little knowledge of this area, and, therefore, there is no definite concept of a media product.

Before we begin to consider a media product, we need to distinguish between "goods", "services", and "products". In Russia, a more common approach to this issue is given to foreign experience. Here, the phrase "media product" is a generalizing word, a term. The term itself is actively used both in Russian journalism and abroad [3, 4, 8, 10].

The development of mass communication and competition influenced the creation of media products of any format. As a consequence, the conditions of production of the advertising product have changed. That is why the term "infobusiness" is defined as the sale of information that carries a useful component and which can then be applied in practice.

Advertising is the result of displaying reality in the format of publicistically limited emotionally colored information, which is designed to convey meaningful information about a product or service to people.

Most researchers recognize this fact of the impact of advertising information on the basis of convincing visual and advertising images $[6,12]$.

Advertising is a fairly large business segment. It is worth noting its direct impact on both the producers of a particular product and the consumers of these goods. It is known that any item of goods or product should be interesting to the buyer, otherwise the demand for the product will fall.

\section{Research Questions}

It is worth noting that the advertising business has noticeably shifted the layer of human values. Previously, special attention was paid to the spiritual side of a person, his moral qualities and values. At present, consumer qualities are placed above spiritual and human values. The peculiarity of advertising is that absolutely on all commercials where either product is advertised, a person is always happy that he has acquired the sold product. A natural phenomenon is that a person who has seen such an advertisement wants to purchase it, and does everything possible for this. We will not deny that advertising is a powerful tool affecting a person. It sets a certain pace of development, creates new opportunities, dictates recent trends, etc. It manipulates feelings of happiness, pleasure, calls for wealth, defines gender roles, eliminates old cultural traditions, adversely affects young people, extols the role of business in society thus actively influencing traditions, customs, habits, lifestyles, the system of values of individuals, forming "its" morality and psyche.

At the moment, the regional media space of Mordovia is presented by such types of advertising as:

a) commercial - as a way of making a profit;

b) institutional - contributes to the development of any organization, brand;

c) industrial - advertising of industrial products;

d) consumer - for development in the sphere of goods and services.

Part of the advertisement is calculated for campaigning in favor of the goods or services, but this advertisement also carries information in the form of the existence of an advertiser, its goods or services and information acting as arguments in favor of a particular goods or service. The quality and reliability of the product is important for both advertisers and consumers. Relevance and scope are essential content parameters.

Such a set of positive aspects of advertising, mass communications indicates the initial stage of development of the regional information market. Besides, it is worth paying attention to the fact that the digital indicators reflect a stable, consistent movement of regional society from the industrial-public to the publicconsumer stage of development. This confirms the fact that a fairly large number of media platforms are occupied by consumer advertising. We consider it necessary to indicate that indirect advertising of goods and services is the most accessible for advertisers, since its parameters are primarily available.

Institutional advertising, which recommends a particular firm or a brand, is a fairly modest print segment at the regional level. There are few industrial enterprises in the region, and the products of advanced organizations do not need any additional promotion. 
Sustained growth is characterized by industrial advertising, which is somewhat characterized by "downturns", which may be explained by seasonal changes in the functioning of joint-stock companies, which have their own circularity. In general, the small growth in industrial production steadily achieved by the Republic of Mordovia over the past ten years is reflected in the qualitative and quantitative improvement of the corresponding type of advertising.

The content analysis of the advertising market of Mordovia showed that advertising companies cover a multimedia: radio, TV, print, banners. Before choosing a particular media for advertising, the advertiser identifies the compliance of the media with the goals, product criteria, the popularity of the media, the range of media distribution, and the advertising charge.

Most advertising companies are represented on print media pages, and this is justified, since the cost of advertising on television is much higher. It is believed that printing is one of the powerful platforms for advertising. The advantages of this type of media include the distribution range. There are newspaper and journal periodicals, and it is newspaper advertising that is more rapid than journal advertising. But in magazines it looks brighter due to the synthesis of image and text. In the newspaper, on the contrary, advertising is placed mainly in text version. Most of the content in regional publications is occupied by advertisements for commercial enterprises and their managers. Interactive mass communication capabilities modify the information product at both the expression and content levels.

Commercial activity has become a fact of Russia's reform life, but its path, which it broke through in regional conditions with difficulty, compared to metropolitan conditions, is more conservative. Besides, commercial advertising masks its profitable side.

The Saransk City Rankings online magazine was registered in the information space of Mordovia. The distribution mechanism of the publication is characterized by the specifics of the Internet. The publication is promoted in the Internet space through Google, Yandex and other search engines, as well as in social media. The direction of the publication, which implies the compilation of all kinds of rankings, provides fertile ground for advertised objects in these rankings. The Saransk City Rankings uses direct advertising on the site (in the form of clickable banners), social media sites in the form of posts with links to the advertised product or service as a way of income.

The editors of the online publication claim that they are not engaged in advertising, but sometimes links to the photographer or leading wedding events still appear on the pages. It is difficult to convict the editors of hidden advertising, since the opportunity to contact concerning advertising on the site is provided: "Advertising is evil. We wait for letters from everyone ready to go to the dark side in the mail: one@.cityratings.ru.

Due to advertising, the product is publicized and is more popular than unreleased goods. Advertising has its own distribution channels. Such channels include print, radio, TV, etc. The economy has quite diverse areas of advertising activity - manufacture of household items, educational services, medicine, politics, election campaigning, etc.

Advertising involuntarily forces people to purchase a particular product, making it clear that everything is material in this world. Therefore, everyone who belongs to the side of consumers and creators, as well as to the promotion of goods plays an important role in the world. Today we can often find the image of a prepared, trained mother in advertising who knows absolutely everything about the health and upbringing of children. The maternal role in this case is not accidental, since it is the personification of authority, a stable concept of mass media advertising. Family today is a success.

"Multimedia" became the reaction to the transformation of audience requests. Multimedia in the modern media industry is understood in no way other than the combination of two or more media. This allows using audio and video content simultaneously with the transfer of information. That is why the multimedia system may be represented as an information system in which all kinds of media interact, and the final products complement each other.

Let us consider one of the common genres of online journalism. This is primarily a multimedia story or a multimedia article. This genre represents a system of convergence elements, where the interactivity of the provided information comes to the fore.

\section{Purpose of the Study}

The purpose of the study is to show the activities of the media in terms of accessibility of mass participation in communication, not only as a consumer, but also as a producer of advertising information; to designate communication itself as a process representing the system of information-sharing relationships; to pay attention to the text elements of the system, among which there are information products broadcast by the media. This requires the involvement of new, relatively studied topics of theoretical and methodological approaches that make it possible to substantiate the presence of a spiritual component in advertising activities.

\section{Research Methods}

Research methods are represented by the combination of different research approaches - systemic, axiological, verbal-centric, contextual, formalized, caused by the logic of the movement of concepts.

The main method was the structural-functional analysis - this method reflects the dynamic concept of the massmedia structure, since it allows identifying semiotically significant aspects of advertising texts, their mutual relations in a mass media product, which is especially relevant in journalistic meta-language. 


\section{Findings}

The results of the study showed that the introduction of new means of access to information such as the Internet immeasurably expands the functions of the media as one of the leading sources of dissemination and consumption of all types of information, opening a different level of media participation in social, political, social and spiritual spheres.

It was revealed that advertising is a kind of phenomenon of our time developed by society and, subsequently, became an important part of it. The functions of social communication (informative, expressive, pragmatic and managerial) are used in the process of advertising impact on the communicant. In search of ways to create effective advertising, the advertisers often turn to semiotics - science that explores signs. The iconic system in advertising communication includes words, images, color, sounds, noise, voice makeup. Each of them has a specific function. In particular, the iconization function (image of an object): an arrow is used as a graphical reception to indicate the direction, or, an exclamation mark as a means of paying special attention.

For example, the employees of the analyzed online publication Saransk City Rankings - http://cityratings.ru/ -visit city institutions, test their goods, services and based on their observations create rankings of certain products, goods, services, organizations, personalities. Thus, the "People" feature publishes such rankings as "The most beautiful photo model of Saransk", "Top 10 football players of Saransk", "Top enviable brides of Saransk". The "Food" feature offers such rankings as "Where is the best barbecue in Saransk", "The most delicious carbonar paste in the city" and "Where to find a lenten menu in Saransk". Before the ranking table, a journalist posts the longread "How we did it", which defines the place in the ranking.

Every week, on Friday, The City Rankings employees tell where to have fun and benefit from a weekend and, importantly, at what price.

The result of our analysis showed that the ranking is presented in the form of a post, where each position is given by a text and a graphic component. The design of the site is made in the popular block style - division into three blocks.

The main page focuses on bright images to articles, many of which are animated. The headings use a "game" with a font: italics or bold selection allow indicating semantic accents in the title of the material. A particular section made on a red background and urging the reader to watch all the news of this section is attached to each post on the main page. The promotion of the advertising product takes into account the modification of a verbal language, the ability to confirm the advertising information. These are peculiar means of advertising effect.

\section{Conclusion}

Advertising shapes people's values, lifestyles. It shows us who we should be, and what a person must strive for. Advertising has its own educational function, which is very important in shaping human values.

Advertising has much in common with such a phenomenon as mass culture, mass art. Mass art is openly used for mass sales. An example is the appeal in the advertising text to the names of book products, film fans, popular magazines and newspapers. Therefore, advertising is a natural and important component of mass culture: elements such as the mode of distribution, the nature of objects created by advertising, and the degree of impact are similar. That is why mass culture and advertising complement each other and serve a kind of mechanism that extends the range of functioning.

Given the indirect and direct influence of advertising on processes and phenomena in the field of economics, politics, spiritual production, it can be argued that it significantly corrects modern culture.

The entire information and advertising process is reflected in the development of regional advertising and communication channels. Trends in the development of communication channels are close to the development trends related to the federal level, but the share of regional life is still reflected in this.

Advertising information fully and efficiently displays the characteristics of the region's everyday life, and regional media, in particular periodicals are more involved in the display. This trend makes it possible to conclude that the region has a stable socio-political situation, as well as predict the transition of public interests to social issues. An interweaving of interests such as the desire for entertainment and solving everyday issues creates the prepared basis for advertising information. Summing up, we can say that advertising information quite fully reflects social life in the region, and mass media, in turn, are the engine of the information market.

With the development of technologies, we can talk about a new type of culture - on-screen, where information is displayed through the use of on-screen means: picture, sound techniques, contour, photo editor all this is aimed at the development of advertising.

\section{References}

1. V.I. Antonova, S.A. Rzhanova, A.A. Rzhanov, Advertising text in the format of television broadcasting (using the example of the NTM channel of Mordovia), Bulletin of Ugric Studies, 8(2), 275-283 (2018)

2. R.R. Gazizov, D.A. Bakeeva, Comparative characteristics of genre modifications of internet-portals, Opcion, 35(Special Issue 22), 238-254 (2019). Retrieved from: https://produccioncientificaluz.org/index. php/opcion/article/view/29442/ (date of access: 18.04.2021.) 
3. T.G. Dobrosklonskaya, Medialinguistics: systematic approach to the study of the media language (Moscow, 2008) 203 p.

4. S. Mariani et al., Mass media influence and the regulation of illegal practices in the seafood market, Conservation Letters, 7(5), 478-483 (2014)

5. V.D. Markova, Fundamentals of Marketing (Unity, Moscow, 2000)

6. V.V. Nalimov, G.A. Drogalin, The reality of unrealistic. The probable model of the unconscious: study manual (Moscow, 1995) $105 \mathrm{p}$.

7. S.A. Rzanova, Synergetics of Mass Media Culture and Trends of Postmodernism in the Modern Information Space of Russia, Utopía y
Praxis Latinoamericana, 24 (Extra 5), 399-408 (2019)

8. L.V. Smirnova, Genres of television advertising (Peter, St. Petersburg, 2016) 184 p.

9. V.V. Tulupov, Russian press: design, advertising, typology: study manual (Voronezh, 1996) $203 \mathrm{p}$.

10. P.M. Valkenburg, J. Peter, J.B. Walther, Media effects: Theory and research, Annual review of psychology, 67, 315-338 (2016)

11. F.I. Sharkov, Integrated advertising communications (RIP-Holding, Moscow, 2005) $291 \mathrm{p}$.

12. A. Yakovlev, A. Chuprun, Contextual advertising. Fundamentals, secrets, tricks: study manual for universities (BHV-Petersburg, St. Petersburg, 2008) 304 p. 